\title{
High moon brightness and low ambient temperatures affect sloth predation by harpy eagles
}

\author{
Everton B. P. de Miranda ${ }^{\text {Corresp., } 1}$, Caio F. Kenup ${ }^{2}$, Edwin Campbell-Thompson ${ }^{3,4}$, Felix H. Vargas ${ }^{4}$, Angel Muela ${ }^{4}$, \\ Richard Watson ${ }^{4}$, Carlos A. Peres ${ }^{5,6}$, Colleen T. Downs ${ }^{1}$ \\ ${ }^{1}$ School of Life Sciences, Centre for Functional Biodiversity, University of KwaZulu-Natal, Pietermaritzburg, Pietermaritzburg, KwaZulu-Natal, South Africa \\ 2 Wildlife and Ecology Group, Massey University, Palmerston North, New Zealand \\ 3 Fundación Aguilas de Los Andes, Pereira, Colombia \\ 4 The Peregrine Fund, Boise, United States of America \\ 5 School of Environmental Sciences, University of East Anglia, Norwich, United Kingdom \\ 6 Departamento de Sistemática e Ecologia, Universidade Federal da Paraíba, João Pessoa, Brazil \\ Corresponding Author: Everton B. P. de Miranda \\ Email address: mirandaebp@gmail.com
}

Background. Climate plays a key role in the life histories of tropical vertebrates. However, tropical forests are only weakly seasonal compared with temperate and boreal regions. For species with limited ability to control core body temperature, even mild climatic variation can determine major behavioural outcomes, such as foraging and predator avoidance. In tropical forests, sloths are the arboreal vertebrate attaining the greatest biomass density, but their capacity to regulate body temperature is limited, relying on behavioural adaptations to thermoregulate. Sloths are largely or strictly nocturnal, and depend on crypsis to avoid predation. The harpy eagle (Harpia harpyja) is a sloth-specialist and exerts strong topdown control over its prey species. Yet the role of environmental variables on the regulation of predatorprey interactions between sloths and harpy eagles are unknown. The harpy eagle is considered Near Threatened. This motivated a comprehensive effort to reintroduce this species into parts of Mesoamerica. This effort incidentally enabled us to understand the prey profile of harpy eagles over multiple seasons. Methods. Our study was conducted between 2003 and 2009 at Soberanía National Park (SNP), Panamá. Telemetered harpy eagles were seen hunting and feeding on individual prey species. For each predation event, field assistants systematically recorded the species killed. We analysed the effects of climatic conditions and vegetation phenology on the prey species profile of harpy eagles using generalised linear mixed models.

Results. Here we show that sloth predation by harpy eagles was negatively affected by nocturnal ambient light (i.e. bright moonshine) and positively affected by seasonally cool temperatures. We suggest that the first ensured low detectability conditions for sloths foraging at night and the second posed a thermally unsuitable climate that forced sloths to forage under riskier daylight. We showed that even moderate seasonal variation in temperature can influence the relationship between a keystone tropical forest predator and a dominant prey item. So predator-prey ecology in the tropics can be modulated by subtle changes in environmental conditions. The seasonal effects shown here suggest important demographic consequences for sloths, which are under top-down regulation from harpy eagle predation, perhaps limiting their geographic distribution at higher latitudes. 
1 Revised for Peer $\mathrm{J}$

2

3 High moon brightness and low ambient temperatures 4 affect sloth predation by harpy eagles

5

6

7

8

Everton B. P. Miranda ${ }^{1}$, Caio Fittipaldi Kenup ${ }^{2}$, Edwin Campbell-Thompson ${ }^{3}$, 4 , Félix Hernán

Vargas $^{4}$, Angel Muela ${ }^{4}$, Richard Watson ${ }^{4}$, Carlos A. Peres ${ }^{5,6}$, Colleen T. Downs ${ }^{1}$

${ }^{1}$ Centre for Functional Biodiversity, School of Life Sciences, University of KwaZulu-Natal,

P/Bag X01. Pietermaritzburg, 3209, South Africa

${ }^{2}$ Wildlife and Ecology Group, Massey University, Palmerston North, New Zealand

${ }^{3}$ Fundación Águilas de Los Andes, Pereira, Colombia

${ }^{4}$ The Peregrine Fund, 5668 West Flying Hawk Lane, Boise, Idaho 83709 U.S.A

${ }^{5}$ School of Environmental Sciences, University of East Anglia, Norwich NR47TJ, UK

${ }^{6}$ Departamento de Sistemática e Ecologia, Universidade Federal da Paraíba, João Pessoa, Brazil Corresponding Author:

Everton Miranda

Rua F2, n²20, Alta Floreta, Mato Grosso 78580-000, Brazil

Email address: mirandaebp@gmail.com

Running header: Sloth predation by harpy eagles 


\section{Abstract}

27 Background. Climate plays a key role in the life histories of tropical vertebrates. However, tropical forests are only weakly seasonal compared with temperate and boreal regions. For species with limited ability to control core body temperature, even mild climatic variation can determine major behavioural outcomes, such as foraging and predator avoidance. In tropical forests, sloths are the arboreal vertebrate attaining the greatest biomass density, but their capacity to regulate body temperature is limited, relying on behavioural adaptations to thermoregulate.

Sloths are largely or strictly nocturnal, and depend on crypsis to avoid predation. The harpy eagle (Harpia harpyja) is a sloth-specialist and exerts strong top-down control over its prey species. Yet the role of environmental variables on the regulation of predator-prey interactions between sloths and harpy eagles are unknown. The harpy eagle is considered Near Threatened. This motivated a comprehensive effort to reintroduce this species into parts of Mesoamerica. This effort incidentally enabled us to understand the prey profile of harpy eagles over multiple seasons.

Methods. Our study was conducted between 2003 and 2009 at Soberanía National Park (SNP), Panamá. Telemetered harpy eagles were seen hunting and feeding on individual prey species. For each predation event, field assistants systematically recorded the species killed. We analysed the effects of climatic conditions and vegetation phenology on the prey species profile of harpy eagles using generalised linear mixed models.

Results. Here we show that sloth predation by harpy eagles was negatively affected by nocturnal ambient light (i.e. bright moonshine) and positively affected by seasonally cool temperatures. We suggest that the first ensured low detectability conditions for sloths foraging at night and the second posed a thermally unsuitable climate that forced sloths to forage under riskier daylight.

We showed that even moderate seasonal variation in temperature can influence the relationship 
50 between a keystone tropical forest predator and a dominant prey item. So predator-prey ecology

51 in the tropics can be modulated by subtle changes in environmental conditions. The seasonal

52 effects shown here suggest important demographic consequences for sloths, which are under top-

53 down regulation from harpy eagle predation, perhaps limiting their geographic distribution at

54 higher latitudes.

55

56 


\section{Introduction}

58 Predation is a central theme in ecology and evolution, driving morphological, physiological, and

59 behavioural responses in prey species to the threat of death or injury (Genovart et al., 2010).

60 Both the nature and magnitude of predation as a dominant ecological force are affected by

61 seasonality (Darimont \& Reimchen, 2002). However, the seasonality of predator-prey

62 relationships in tropical forests is at best considered to be subtle compared with temperate and

63 boreal regions, because of the comparatively low variation in day length and ambient

64 temperature (Forsythe et al., 1995). Nevertheless, tropical forests can experience considerable

65 seasonality in leaf flushing and fruiting as a response to climatic variables (Mendoza, Peres \&

66 Morellato, 2016). While available data suggests that climatic conditions in tropical environments

67 have strong effects on animal activity (Foster et al., 2013; Cid, Oliveira-Santos \& Mourão,

68 2015), there are relatively few studies about the nature of such effects on predator-prey

69 interactions.

70 Seasonally elevated rainfall and the resulting responses in vegetation growth can provide

71 food and cover for many arboreal taxa in tropical forests (Haugaasen \& Peres, 2009).

72 Conversely, the dry season often induces leaf abscission in trees and woody lianas (Souza,

73 Gandolfi \& Rodrigues, 2014), which may limit food availability and shelter to arboreal folivores.

74 The combination of reduced cover and limited food resource availability can enhance predation

75 risk (Menezes, Kotler \& Mourão, 2014; Menezes, Mourão \& Kotler, 2017). The seasonal

76 variation may modify the range of thermal microhabitats available to a prey species. As

77 endothermic forest specialists, sloths (genus Bradypus and Choloepus, order Pilosa) exhibit

78 relatively low basal metabolic rates and can only partially regulate body temperature (Pauli et al.,

79 2016). Therefore, they need to bask and can be affected by even mild variation in habitat cover

80 and thermally inappropriate microhabitats (Peery \& Pauli, 2014; Giné et al., 2015), to the extent 
81 that temperature seasonality is highly influential on sloth behavioural ecology (Moreira et al., 82 2014).

Sloths from the Bradypus and Choloepus genus differ in their biology. Choloepus are 84 more vigorous (Pauli et al., 2016), larger ( 6kg, Wetzel \& Montgomery, 1985), have a higher 85 body temperature (Vendl et al., 2016), and a more diversified diet (Dill-McFarland et al., 2016). 86 Bradypus sloths fit the stereotypical sluggish behaviour of sloths (Pauli et al., 2016), are smaller 87 ( $4 \mathrm{~kg}$; Wetzel \& Montgomery, 1985), have a relatively low body temperature (Vendl et al., 88 2016), and feed on leaves exclusively (Dill-McFarland et al., 2016). Finally, two-toed sloths 89 (Choloepus spp.) are nocturnal, whereas three-toed sloths (Bradypus spp.) are cathemeral 90 (Sunquist \& Montgomery, 1973; Giné et al., 2015).

91 Likewise, moonlight is likely to alter animal behaviour by affecting detectability of both 92 predators and prey at night (San-Jose et al., 2019). Lunar phobia by mammals is widely justified 93 as a strategy to prevent predation (Cozzi et al., 2012). However, a metanalysis by Prugh and 94 Golden (2014) showed that the response to lunar light was typically idiosyncratic. While 95 visually-oriented mammals have an increased activity response to lunar light, mammals that have 96 weak vision - like sloths - generally decrease activity on bright nights (Prugh \& Golden, 2014) 97 and therefore are less likely to suffer predation.

We can expected that the seasonality of predator-prey relationships involving sloths might be affected by even subtle climatic fluctuations in ambient temperature. Sloths are important prey species that rely heavily on crypsis to avoid predation, rather than evasive responses once they are detected (Touchton, Hsu \& Palleroni, 2002). However, studies

102 attempting to identify the cues leading to seasonal changes in prey activity and predation are 103 inherently hindered by small sample sizes. While apex predators have profound effects on 
104 ecosystem structure and function (Terborgh et al., 2001), they are difficult to study, rendering 105 this lack of knowledge almost impossible to overcome.

106 The harpy eagle (Harpia harpyja; Fig 1) is considered Near Threatened by the IUCN 107 (Birdlife International, 2017), mainly because of human persecution (Muñiz-López, 2017) and 108 habitat loss, which have extirpated these mega-raptors from $41 \%$ of their former historical range 109 distribution (Miranda et al., 2019). Harpy eagles are an apex predator that specialises on sloths, 110 relying heavily on these prey species wherever they co-occur (Aguiar-Silva, Sanaiotti \& Luz, 111 2014; Miranda, 2015). Harpy eagles hunt passively by visually scanning and listening to the 112 forest canopy (Touchton, Hsu \& Palleroni, 2002). They are unique among eagles having a large 113 retractable facial disc to enhance their hearing (Ferguson-Lees \& Christie, 2001). Harpy eagles 114 are the Earth's largest eagles. Being large-sized, they can prey on sloths of any age (Aguiar115 Silva, Sanaiotti \& Luz, 2014), including adult individuals of all continental sloth species 116 (Miranda, 2018). Harpy eagle-sloth predator-prey systems are therefore ideal candidates to 117 investigate how changes in climate and moonlight may affect multispecies predation rates. 118 The Peregrine Fund has lead a comprehensive effort to reintroduce this species into parts of 119 Mesoamerica (Campbell-Thompson et al., 2012; Watson et al., 2016). This effort, spanning from 1202003 to 2009 , incidentally enabled us to understand, for the first time, the prey profile of harpy 121 eagles over multiple seasons. We explored environmental determinants of prey capture rates of reintroduced harpy 123 eagles in Soberanía National Park; a tropical protected area in Panamá. Our goals were twofold:

124 (1) to assess the effects of seasonality — like temperature, rainfall and leaf decidousness — on

125 sloth capture rates by harpy eagles; and (2) to assess how moonlight could affect sloth and 126 nocturnal prey predation rates. We predicted that: (1) sloth predation rates would increase with 
127 low temperatures, high rainfall and low leaf cover; (2) sloth and nocturnal prey predation rates

128 would increase with low moon brightness.

129

130 Materials \& Methods

131 StUdy SITE. - Our study was conducted between 2003 and 2009 at Soberanía National Park

132 (hereafter, SNP), a 19,545 ha protected area in eastern Panama along the banks of the Panama

133 Canal $\left(9^{\circ} 07^{\prime} 13^{\prime \prime} \mathrm{N}, 79^{\circ} 39^{\prime} 37^{\prime \prime} \mathrm{W}\right)$. The vegetation of SNP consists of semi-deciduous,

134 seasonally moist tropical forest, most of which is now advanced ( $>80$ years) secondary forest

135 (Bohlman, 2010). The area has most of the staple prey species targeted by harpy eagles (Aguiar-

136 Silva, Sanaiotti \& Luz, 2014), including three-toed sloths (Bradypus variegatus), Hoffman’s

137 two-toed sloths (Choloepus hoffmanni), white-nosed coati (Nasua narica), northern lesser

138 anteater (Tamandua mexicana) and mantled howler monkeys (Alouatta palliata), all of which are

139 either strictly arboreal or scansorial mammals. The Peregrine Fund had conducted experimental

140 harpy eagle releases within SNP since 1997 (Muela et al., 2003; Watson et al., 2016), therefore

141 we assumed that none of the prey species here were predator-naïve during our study.

142 The SNP has a marked dry season from December to April and a wet season from May to

143 November. The wet season concentrates $85.3 \%$ of the annual rainfall, which averaged 2,242 $\mathrm{mm}$

144 p.a. for 2003-2009. During the dry season, the mean, minimum and maximum ambient

145 temperatures were $27.3,22.1,33.0^{\circ} \mathrm{C}$, respectively, and slightly warmer than the corresponding

146 temperatures during the wet season $\left(26.5,23.2,30.9^{\circ} \mathrm{C}\right.$, respectively). Daily climate data were

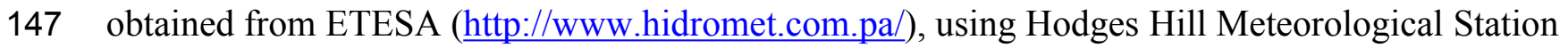

148 data for rainfall (15 km from the release site) and the Tocumen Station for data on temperature 
149 (43 km from the release site). A Walter-Lieth climate diagram describing the seasonality of

150 rainfall and ambient temperature in the park was created (Supplementary Information Fig. S1).

151 HARPY EAGLE PREY PROFILE.-Before final release, captive-bred harpy eagles were soft-

152 released at SNP by a process known as hacking (Muela et al., 2003). This allowed harpy eagles

153 to learn how to hunt, as would occur in the wild (Muñiz-López et al., 2016). Further details on

154 the harpy eagle reintroduction protocols and results are available in Campbell-Thompson et al.

155 (2012) and Watson et al. (2016). Harpy eagles were fitted with both radio-telemetry and GPS

156 tags. During soft releases, they were fed thawed rats and rabbits, always using a blind to avoid

157 food conditioning with humans. Foraging independence was defined on the basis on an eagle

158 being able to make two unassisted successive kills within 20 days or survive 30 days without

159 food provisioning, thereby demonstrating that it was able to hunt self-sufficiently. Both regular

160 radio- and global position system (GPS)-tracking leading to visual contact with each telemetered

161 eagle was required to check its body condition.

162

As the reintroduced hapy eagles were captive-born sub-adults (5-22 months; Campbell-

163 Thompson et al., 2012) from captive stock maintained by The Peregrine Fund, we performed an

164 a priori graphical analysis to ensure that the diet of reintroduced harpy eagles was similar to that

165 of wild adult individuals. We did so by dividing the number of captured prey items within blocks

166 of 25 samples (which adequately represents the main prey species; Miranda 2015) and

167 distributed them according to ontogeny or experience. We defined ontogeny as age in months for

168 any given predation event, whereas we defined experience as any given predation event relative

169 to the number of days since the first wild prey item was captured. Neither ontogeny nor

170 experience affected harpy eagles' patterns of predation as there was no evidence of nested

171 patterns that would be expected if shifts in prey preferences occurred (Supplementary 
172 information Fig. S2 and S3). We therefore consider hunting patterns by reintroduced harpy

173 eagles comparable with those of wild adults, and this was consistent with previous reports

174 (Touchton, Hsu \& Palleroni, 2002). The spatial distribution of those kill sites, as well as the

175 location of the release site and meteorological stations within SNP are shown in Fig. 2.

177 harpy eagles were seen hunting and feeding on individual prey species. For each predation event, 178 field assistants systematically recorded all species killed (whenever identification to the level of 179 species was possible). Field assistants were instructed to remain as inconspicuous as possible 180 and leave the eagles alone as soon as observations were recorded. Prey items of known species 181 identity were recorded during all months of the year, over the 7-year study, although 182 observations were typically sparser during the month of November.

183 We related measures of climatic seasonality and vegetation phenology to the prey species

184 profile of harpy eagles. Daily climatic data on precipitation and ambient temperature, were 185 obtained from nearby meteorological stations. Data on the phases of the lunar cycle at a daily 186 resolution over the entire study period were obtained from http://www.astronomyknowhow.com. 187 We used the percentage of moon shade cover per night as a proxy for light availability. We used 188 the normalised difference vegetation index (NDVI) as a proxy for canopy leaf deciduousness, 189 where NDVI $=(I R-R) /(R+I R)$, IR being the near- infrared LANDSAT band 4 and $R$ the red 190 LANDSAT band 3. NDVI values were calculated using georeferenced LANDSAT images obtained 191 for all months of the year during the study period. NDVI is a measure of vegetation 'greenness', 192 rather than deciduousness, but is highly correlated to leafing cycles (Bohlman, 2010). For each 193 prey detection event, we estimated the NDVI score of all $30 \mathrm{~m} \times 30 \mathrm{~m}$ pixels within a $1 \mathrm{~km}$ 194 radius of the location of each predation event for the nearest five dates of LANDSAT images 
195 available for that period. We then interpolated these indices to estimate the composite NDVI

196 metric for the detection date of each prey item.

197 We ran two batches of generalised linear mixed-effects models (GLMM) using as

198 response variables (1) the probability of any given prey item being a sloth (either Bradypus or

199 Choloepus) and (2) the probability of any given prey item being nocturnal. Because the set of

200 environmental covariates for each model was large, we used a backwards AIC-based stepwise

201 algorithm to select the most important variables for each fixed-effect model, adding the random

202 effect afterwards. All GLMMs were run using a binomial error structure and the logit link

203 function, and bird identity as a random effect on the intercept. All variables used were checked

204 for covariance using the Variance Inflation Factor (VIF). All analyses were run using the R 3.6.1

205 platform. Environmental covariates used in each GLMM are presented in Supplementary

206 information Table S1. All source codes used in the analyses are available at

207 https://github.com/KenupCF/HarpySlothPredation.

208 The Peregrine Fund Harpy Eagle Restoration Program complied with the laws of Panamá

209 during the time in which the project was performed, with permits granted by National

210 Environmental Authority of Panama (ANAM, at present MiAmbiente and SISBIO\#58533-5).

\section{Results}

213 We recorded a total of 200 harpy eagle predation events, from which we obtained positional data

214 for 189 prey items, 173 of which were identified. These prey items were killed by 33 harpy

215 eagles during six dry seasons and six wet seasons during the 7 years of study. This amounted to

21688 prey samples during the dry seasons and 85 samples during the wet seasons. The temporal

217 distribution of predation records and the functional groups of prey species showed that sloths 
218 were by far the most important prey species for harpy eagles (Fig. 3). Two sloth species

219 represented $65.3 \%$ of the harpy eagle diet in terms of the overall numeric prey profile, of which

220 brown-throated sloths, Hoffman's two-toed sloths and unknown sloths represented 34.1\%, 15.6\%

221 and $15.6 \%$ of all prey items, respectively. Second to sloths, the next most significant dietary

222 contributors to harpy eagles were white-nosed coatis (7.5\%), northern lesser anteaters $(6.9 \%)$ and

223 mantled howler monkeys (5.2\%). Further information on the prey species composition are shown

224 in Table 1.

225 Sloth predation rates increased significantly during low moon brightness $(\beta=-0.648, \mathrm{p}=$ 226 0.0116) and low ambient temperatures with marginal statistical significance $(\beta=-0.508, \mathrm{p}=$

227 0.0535; Fig. 4). Harpy predation on nocturnal animals was weakly affected by low moon

228 brightness (Fig. 4), but this lacked sufficient statistical significance $(\beta=-0.392, p=0.1461)$.

229 Rainfall and leaf deciduousness had no discernible effect in any of our models. Statistical results 230 are summarised in Table 2. 


\section{Discussion}

233 Although environmental conditions either increase prey vulnerability or provide an advantage to 234 sit-and-wait and pursuit predators (Doody, Sims \& Letnic, 2007; Prugh \& Golden, 2014), little 235 has been documented on this topic in closed-canopy tropical forest ecosystems. In harpy eagle236 sloth predator-prey systems, we showed increases in sloth nocturnal activity under elevated

237 moon brightness and cryptic behaviour during the day provided mechanisms of escaping

238 detection by harpy eagles. We also showed an increase in predation rates under cool

239 temperatures, which may induce further diurnal activity of sloths. Finally, we examined the roles

240 of leaf flush and rainfall on harpy eagle prey choice, but neither had a detectable effect on sloth

241 predation rates. These results pose interesting questions about the consequences of temperature

242 and moon brightness to this keystone Neotropical forest predator and its dominant prey species.

243 Moonlight has been shown to have contradictory effects on nocturnal mammal activity

244 patterns in terms of their antipredator strategies. Prey species that can detect predators visually

245 and anticipate their attacks with evasive maneuvers may increase foraging activity under high

246 levels of moonlight, whereas those that cannot decrease activity (Prugh \& Golden, 2014). Sloths,

247 however, typically prefer to sleep at night in environments where they evolved with predator 248 presence (Voirin et al., 2014), and in other areas generally showing greater fear of diurnal

249 predators as harpy eagles. Indeed, there is anecdotal evidence of increased sloth activity during

250 full moon phases (Beebe, 1926). Sloths are known to be lethargic and have extremely poor

251 vision, while harpy eagles typically attack from distances of less than $30 \mathrm{~m}$ during daylight

252 (Touchton, Hsu \& Palleroni, 2002). We, therefore, expected that sloths reduce their overall 253 activity during the day, instead foraging at night under bright moonlit to reduce predation risk,

254 which significantly reduces the probability of successful attacks by diurnal harpy eagles. Success 
255 rates of harpy eagles predation on sloths is generally high compared with visually oriented prey:

$25655 \%$ of all attacked sloths are successfully killed, while only $33 \%$ of visually oriented prey are

257 successfully killed if they had been attacked (Touchton, Hsu \& Palleroni, 2002). This may be the

258 underlying adaptive reason why sloths are inactive during the day if bright nights are available as

259 foraging time, neutralising search images of diurnal predators and greatly reducing their

260 detection probability by harpy eagles. Further sloth telemetry studies would provide

261 confirmatory evidence.

262 In addition to the reduced predation levels of sloths during bright moon nights, we

263 showed that as ambient temperatures increased, predation rates declined. Presumably, this

264 happened because of the increased daytime activity levels of this endotherm, which is prone to

265 metabolic torpor under cooler weather conditions, especially at night (Giné et al., 2015). It has

266 been shown, for instance, that the nocturnal activity of the maned sloth (Bradypus torquatus) is

267 inhibited by lower ambient temperatures (Chiarello, 1998). Predation rates of sloths by harpy

268 eagles were higher during colder conditions, which likely induce compensatory activity by sloths

269 during the warmer daytime. Basking behavior of sloths increases with lower ambient

270 temperatures along altitudinal gradients in mountainous areas (Urbani \& Bosque, 2007). Another

271 possible explanation for the temporal changes in sloth predation rate could result from its

272 reproductive behaviour. However, the literature shows weak and idiosyncratic evidence for

273 seasonal breeding for both sloth species present in our study area (Taube et al., 2001). These

274 features reinforce our premise that behavioural crypsis is the main antipredator strategy of sloths,

275 which we suggest to be the underlying reasons for the patterns observed in our study. Indeed, the

276 latitudinal boundaries of the geographic distribution of sloths are far more restricted than those of

277 harpy eagles (Moreira et al., 2014; Miranda et al., 2019). Sloths of the Choloepus genus are 
278 distributed over tropical Central America and the pan-Amazonian region, while Bradypus also 279 occur over the northern section of Atlantic Forest (Emmons \& Feer, 1997). Predation by harpy 280 eagles may play a key role in limiting sloth geographic distribution — and altitudinal ranges281 given that sloths would be required to compensate for cooler temperatures in the southern 282 Atlantic Forest or higher regions by increasing levels of diurnal activity (Chiarello, 1998; Urbani $\&$ Bosque, 2007). Therefore, this would inhibit extended periods of inactivity induced by cool temperatures, but increase temporal activity overlap with diurnal predators. predation, a pattern that could also be explained by low predation risk resulting from the cessation of harpy eagle activity during rainy weather (Touchton, Hsu \& Palleroni, 2002), or even distance from the meteorological stations, inducing error. Leaf abscission presented no effects on predation of sloths. Although we predicted increased probability of arboreal prey detection under leafless conditions in the semi-deciduous forests of central Panama, forest areas dominated by leafless trees and/or woody lianas may be consistently avoided by prey species relying on concealed foraging activity (Menezes, Kotler \& Mourão, 2014; Menezes, Mourão \& Kotler, 2017). For a sloth, leafless tree crowns offer little if any protective cover and no food resources. Our robust methods to estimate levels of deciduousness combined with a wide buffer describing the likely sight range of potential kills suggest that arboreal habitats lacking foliage cover would be avoided not only by prey species but also by harpy eagles, thereby at least partly explaining why deciduousness had no effects in any of our models. environmental covariates, and the fact that these large diurnal raptors can frequently successfully 
301 of nocturnal mammals were associated with darker nights, when nocturnal species typically

302 preyed by harpy eagles (anteaters, opossums, and armadillos) are expected to be more active

303 given their poor ability to anticipate incoming predators visually (Caro, 2005; Prugh \& Golden,

304 2014). The harpy eagle sit-and-wait predation strategy is further enhanced by their retractable

305 facial disc, which performs the same function as in strictly nocturnal raptors (i.e. owls), of

306 improving acoustic detection of prey. Combined with extremely acute vision, which is likely

307 associated with a high density of photoreceptor cells in the retina typical of many diurnal raptors

308 (Lisney et al., 2013), harpy eagles are superbly capable of locating inconspicuous prey, enabling

309 them to be the only Neotropical apex predator to specialise on the highly secretive sloths

310 (Miranda, 2015; Miranda, Menezes \& Rheingantz, 2016). Harpy eagle activity patterns can be

311 investigated with further research using either intensive telemetry-assisted follows or camera

312 trapped nests. By including nocturnal telemetry or motion-sensitive telemetry devices on

313 monitoring schedules or confirming that harpy eagles can deploy crepuscular/nocturnal hunting

314 effort at the time of nesting (e.g. evidenced by nocturnal prey delivery) would largely solve this 315 question.

316 Our results suggest important consequences for patterns of prey mortality through the

317 tropical seasons of Neotropical forests. We, therefore, suggest that researchers, conservationists

318 and practitioners can learn from natural fluctuations in predator-prey systems when designing

319 management actions (such as reintroduction, release and translocation efforts) of both harpy

320 eagles and their prey, since some of these prey species are also threatened (Catzeflis et al., 2008;

321 Moreira et al., 2014; Suscke et al., 2016). For instance, consequences of the harpy eagle

322 reintroduction on the endemic maned sloth which is listed as Vulnerable in the Brazilian Atlantic

323 Forest needs careful evaluation. 


\section{Conclusions}

326 We showed that the probability of harpy eagles preying on sloths decreased in response to

327 nocturnal high moon brightness and increased with low temperatures. This almost certainly

328 occurs because sloths respond to low temperatures foraging more in the daytime, and circumvent

329 high diurnal detectability by foraging on bright moonlit nights when they are not exposed to

330 visually oriented predators. These conceptually simple conclusions result from overcoming the

331 formidable challenges of monitoring the diet of apex predators in tropical forests for extended

332 periods. We further note that the seasonal effects we uncovered here suggest important

333 consequences for herbivore prey species, whose populations are likely regulated by top-down

334 predation from harpy eagles and other top predators. The magnitude of cyclic changes in

335 predator-prey interactions shown here potentially are even stronger in more seasonal tropical

336 and subtropical forests experiencing cooler seasons, higher altitudes or prolonged flood pulses.

337 Further studies on a diverse set of predator and prey assemblages in tropical forests elsewhere

338 would help fill this knowledge gap.

339

340 Acknowledgements

341 We thank the many institutions and staff who have participated in The Peregrine Fund's Harpy

342 Eagle Restoration Program. We also thank hack-site attendants for field assistance. Everton

343 Miranda's logistical support was given by the Peugeot-ONF Carbon Sink Reforestation Project,

344 based at the São Nicolau Farm in Cotriguaçu, Mato Grosso, Brazil. This Project is a Peugeot

345 initiative to fulfil some of the Kyoto Protocol directions and is run by the ONF-Brasil enterprise. 
346 CTD is grateful to the University of KwaZulu-Natal (ZA) and the National Research Foundation

347 (ZA) for funding. Marcus Canuto, Jose Vargas and Alexander Blanco provided useful

348 discussions, improving a previous version of the manuscript. The Peregrine Fund Harpy Eagle

349 Restoration Program complied with the laws of Panamá during the time in which the project was

350 performed. We are grateful for the constructive comments of Mario Fernando Garces Restrepo

351 and an anonymous reviewer.

352

\section{References}

354

355

356

357

358

359

360

361

362

363

364

365

366

367

368

369

370

371

372

373

374

375

376

377

378

379

380

381

382

Aguiar-Silva F, Sanaiotti T, Luz B. 2014. Food habits of the Harpy Eagle, a top predator from the Amazonian rainforest canopy. Journal of Raptor Research 48:24-45.

Beebe W. 1926. The three-toed sloth, Bradypus cucullinger cucullinger Wagler. Zoologica 7:167.

Birdlife International. 2017. Harpia harpyja (American Harpy Eagle, Harpy Eagle). Available at http://datazone.birdlife.org/species/factsheet/22695998 (accessed February 13, 2018).

Bohlman SA. 2010. Landscape patterns and environmental controls of deciduousness in forests of central Panama. Global Ecology and Biogeography 19:376-385. DOI: 10.1111/j.14668238.2009.00518.x.

Campbell-Thompson E, Vargas FH, Watson RT, Muela A, Cáceres NC. 2012. Effect of Sex and Age at Release on the Independence of Hacked Harpy Eagles. Journal of Raptor Research 46:158-167. DOI: 10.3356/JRR-10-74.1.

Caro T. 2005. Antipredator defenses in birds and mammals. Chicago, USA: University of Chicago Press.

Catzeflis F, J. P, Percequillo A, Bonvicino C, Weksler M. 2008.Chaetomys subspinosus. Available at http://dx.doi.org/10.2305/IUCN.UK.2008.RLTS.T4366A10812988.en

Chiarello AG. 1998. Activity budgets and ranging patterns of the Atlantic forest maned sloth Bradypus torquatus (Xenarthra: Bradypodidae). Journal of Zoology 246:1-10.

Cid B, Oliveira-Santos LGR, Mourão G. 2015. The relationship between external temperature and daily activity in a large rodent (Dasyprocta azarae) in the Brazilian Pantanal. Journal of Tropical Ecology 31:469-472. DOI: 10.1017/S0266467415000309.

Cozzi G, Broekhuis F, McNutt JW, Turnbull LA, Macdonald DW, Schmid B. 2012. Fear of the dark or dinner by moonlight? Reduced temporal partitioning among Africa's large carnivores. Ecology 93:2590-2599.

Darimont CT, Reimchen TE. 2002. Intra-hair stable isotope analysis implies seasonal shift to salmon in gray wolf diet. Canadian Journal of Zoology 80:1638-1642. DOI: 10.1139/z02149.

Dill-McFarland KA, Weimer PJ, Pauli JN, Peery MZ, Suen G. 2016. Diet specialization selects for an unusual and simplified gut microbiota in two-and three-toed sloths. Environmental

Peer] reviewing PDF | (2020:03:46963:2:0:NEW 24 Jul 2020) 
406

407

408

409

410

411

412

413

414

415

416

417

418

419

420

421

422

423

424

425

426

427

428

microbiology 18:1391-1402.

Doody SJ, Sims RA, Letnic M. 2007. Environmental Manipulation to Avoid a Unique Predator: Drinking Hole Excavation in the Agile Wallaby, Macropus agilis. Ethology 113:128-136. DOI: $10.1111 /$ j.1439-0310.2006.01298.x.

Emmons L, Feer F. 1997. Neotropical rainforest mammals: a field guide. Chicago: University of Chicago Press.

Ferguson-Lees J, Christie D. 2001. Raptors of the world. New York, USA: Houghton Mifflin Harcourt.

Forsythe WC, Rykiel EJ, Stahl RS, Wu HI, Schoolfield RM. 1995. A model comparison for daylength as a function of latitude and day of year. Ecological Modelling 80:87-95.

Foster VC, Sarmento P, Sollmann R, Tôrres N, Jácomo ATA, Negrões N, Fonseca C, Silveira L. 2013. Jaguar and Puma Activity Patterns and Predator-Prey Interactions in Four Brazilian Biomes. Biotropica 45:373-379. DOI: 10.1111/btp.12021.

Genovart M, Negre N, Tavecchia G, Bistuer A, Parpal L, Oro D. 2010. The young, the weak and the sick: evidence of natural selection by predation. PloS ONE 5:e9774. DOI: 10.1371/journal.pone.0009774.

Giné GAF, Cassano CR, de Almeida SS, Faria D. 2015. Activity budget, pattern and rhythm of maned sloths (Bradypus torquatus): Responses to variations in ambient temperature. Mammalian Biology - Zeitschrift für Säugetierkunde 80:459-467. DOI: 10.1016/j.mambio.2015.07.003.

Haugaasen T, Peres CA. 2009. Interspecific primate associations in Amazonian flooded and unflooded forests. Primates 50:239-251. DOI: 10.1007/s10329-009-0135-4.

Lisney TJ, Stecyk K, Kolominsky J, Graves GR, Wylie DR, Iwaniuk AN. 2013. Comparison of eye morphology and retinal topography in two species of new world vultures (Aves: Cathartidae). The Anatomical Record 296:1954-1970.

Mendoza I, Peres CA, Morellato LPC. 2016. Continental-scale patterns and climatic drivers of fruiting phenology: A quantitative Neotropical review. Global and Planetary Change 148:227-241.

Menezes JFS, Kotler BP, Mourão GM. 2014. Uniform predation risk in nature: common, inconspicuous, and a source of error to predation risk experiments. Behavioral Ecology and Sociobiology 68:1809-1818. DOI: 10.1007/s00265-014-1790-z.

Menezes JF, Mourão GM, Kotler BP. 2017. Understory cover increases patch use in rodent Thrichomys fosteri. Ethology Ecology \& Evolution:1-10.

Miranda EBP. 2015. Conservation implications of harpy eagle Harpia harpyja predation patterns. Endangered Species Research 29:69-79. DOI: 10.3354/esr00700.

Miranda EBP. 2018. Prey composition of harpy eagles (Harpia harpyja) in Raleighvallen, Suriname. Tropical Conservation Science 11:1-8.

Miranda EBP, Menezes JFS, Farias CC, Munn C, Peres CA. 2019. Species distribution modeling reveals strongholds and potential reintroduction areas for the world's largest eagle. PloS one 14:e0216323.

Miranda EBP, Menezes JFS, Rheingantz ML. 2016. Reptiles as principal prey? Adaptations for durophagy and prey selection by jaguar (Panthera onca). Journal of Natural History 50:2021-2035.

Moreira D de O, Leite GR, Siqueira MF de, Coutinho BR, Zanon MS, Mendes SL. 2014. The Distributional Ecology of the Maned Sloth: Environmental Influences on Its Distribution and Gaps in Knowledge. PLoS ONE 9:e110929. DOI: 10.1371/journal.pone.0110929. 
429

430

431

432

433

434

435

436

437

438

439

440

441

442

443

444

445

446

447

448

449

450

451

452

453

454

455

456

457

458

459

460

461

462

463

464

465

466

467

468

469

470

471

472

473

474

Muela A, Watson R, Mutch B, Heinrich W. 2003. The Harpy Eagle: biology, restoration and hacking procedures. Ciudad de Panamá.

Muñiz-López R. 2017. Harpy Eagle (Harpia harpyja) mortality in Ecuador. Studies on Neotropical Fauna and Environment 30:1-5. DOI: http://dx.doi.org/10.1080/01650521.2016.1276716.

Muñiz-López R, Limiñana R, Cortés GD, Urios V, Limiñana R, Cortés GD, Urios V. 2016. Movements of Harpy Eagles Harpia harpyja during their first two years after hatching Movements of Harpy Eagles Harpia harpyja during their first two years after hatching. Bird Study 3657:509-514. DOI: 10.1080/00063657.2012.722190.

Pauli JN, Peery MZ, Fountain ED, Karasov WH. 2016. Arboreal Folivores Limit Their Energetic Output, All the Way to Slothfulness. The American Naturalist 188:196-204. DOI: 10.1086/687032.

Peery MZ, Pauli JN. 2014. Shade-grown cacao supports a self-sustaining population of two-toed but not three-toed sloths. Journal of Applied Ecology 51:162-170. DOI: 10.1111/13652664.12182.

Prugh LR, Golden CD. 2014. Does moonlight increase predation risk? Meta-analysis reveals divergent responses of nocturnal mammals to lunar cycles. Journal of Animal Ecology 83:504-514. DOI: 10.1111/1365-2656.12148.

San-Jose LM, Séchaud R, Schalcher K, Judes C, Questiaux A, Oliveira-Xavier A, Gémard C, Almasi B, Béziers P, Kelber A, Amar A. 2019. Differential fitness effects of moonlight on plumage colour morphs in barn owls. Nature ecology \& evolution 3:1331-1340.

Souza FM, Gandolfi S, Rodrigues RR. 2014. Deciduousness Influences the Understory Community in a Semideciduous Tropical Forest. Biotropica 46:512-515. DOI: 10.1111/btp.12137.

Sunquist ME, Montgomery GG. 1973. Activity patterns and rates of movement of two-toed and three-toed sloths (Choloepus hoffmanni and Bradypus infuscatus). Journal of Mammalogy 54:946-954. DOI: 10.2307/1379088.

Suscke P, Verderane M, de Oliveira RS, Delval I, Fernández-Bolaños M, Izar P. 2016. Predatory threat of harpy eagles for yellow-breasted capuchin monkeys in the Atlantic Forest. Primates:1-7. DOI: 10.1007/s10329-016-0557-8.

Taube E, Keravec J, Vié JC, Duplantier JM. 2001. Reproductive biology and postnatal development in sloths, Bradypus and Choloepus: review with original data from the field (French Guiana) and from captivity. Mammal Review 31:173-188.

Terborgh J, Lopez L, Nunez P, Rao M, Shahabuddin G, Orihuela G, Riveros M, Ascanio F, Adler G, Lambert T, Balbas L. 2001. Ecological meltdown in predator-free forest fragments. Science 294:1923-1926.

Touchton J, Hsu Y, Palleroni A. 2002. Foraging ecology of reintroduced captive-bred subadult harpy eagles $(<\mathrm{i}>$ Harpia harpyja $<\mathrm{i} />)$ on Barro Colorado Island, Panama. Ornitología neotropical 13:365-379.

Urbani B, Bosque C. 2007. Feeding ecology and postural behaviour of the three-toed sloth (Bradypus variegatus flaccidus) in northern Venezuela. Mammalian Biology 72:321-329.

Vendl C, Frei S, Dittmann MT, Furrer S, Osmann C, Ortmann S, Munn A, Kreuzer M, Clauss M. 2016. Digestive physiology, metabolism and methane production of captive Linné's two-toed sloths (C holoepus didactylus). Journal of Animal Physiology and Animal Nutrition 100:552-564.

Voirin B, Scriba MF, Martinez-Gonzalez D, Vyssotski AL, Wikelski M, Rattenborg NC. 2014.

Peer) reviewing PDF | (2020:03:46963:2:0:NEW 24 Jul 2020) 
475 Ecology and Neurophysiology of Sleep in Two Wild Sloth Species. Sleep 37:753-761.

476 Watson RT, McClure CJW, Vargas FH, Jenny JP. 2016. Trial Restoration of the Harpy Eagle, a 477 Large, Long-lived, Tropical Forest Raptor, in Panama and Belize. Journal of Raptor

478 Research 50:3-22. DOI: 10.3356/rapt-50-01-3-22.1.

479 Wetzel R, Montgomery G. 1985. The evolution and ecology of armadillos, sloths and

480 vermilinguas. Washington, USA: Smithsonian Institution.

481 


\section{Figure 1}

Fig. 1. Harpy eagle preying over sloth.

Adult female harpy eagle (Harpia harpyja) eating a young Two-toed sloth (Choloepus didactylus; Photo: Danilo Mota). 


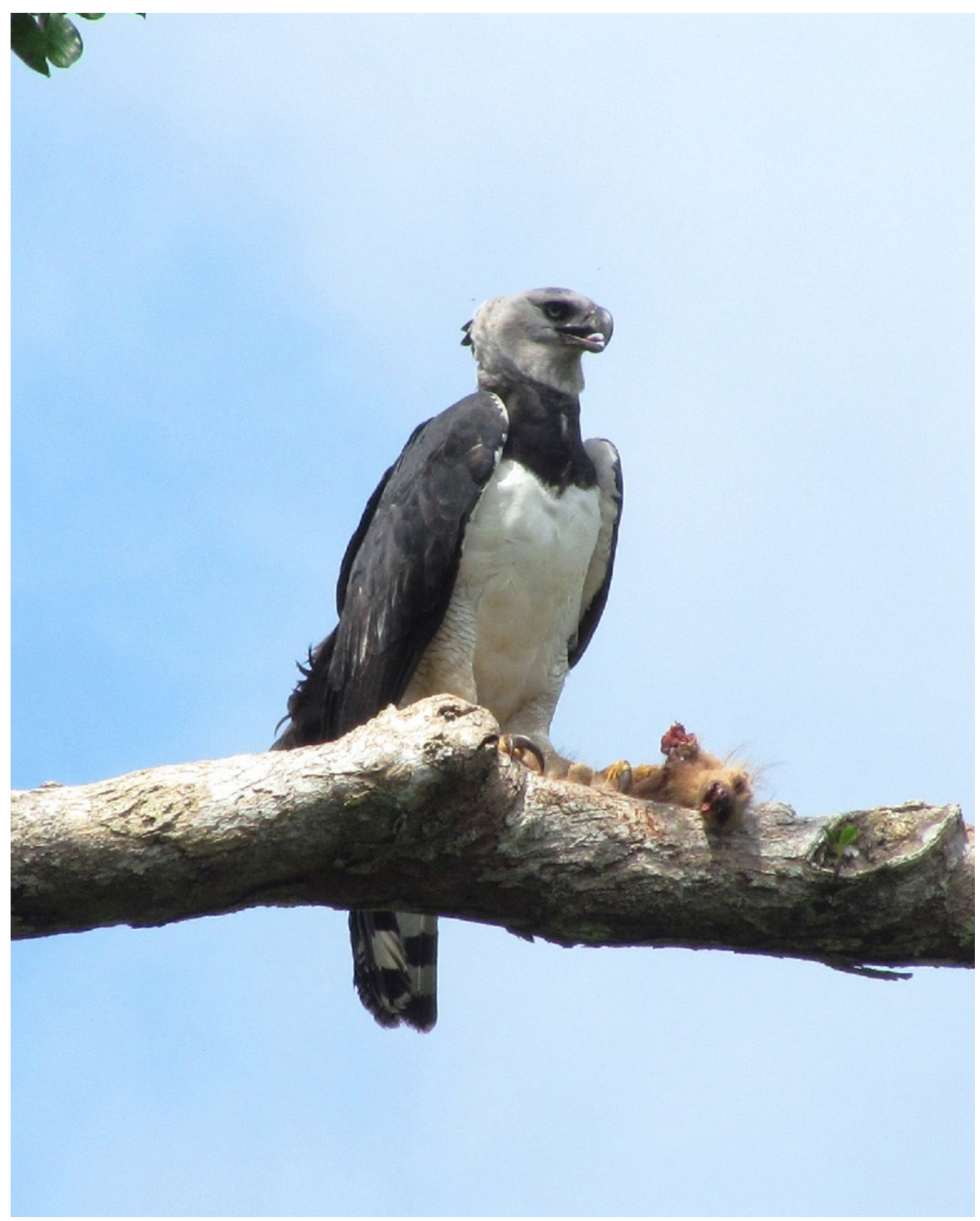


Figure 2

Fig. 2. Study site.

Location of Soberanía National Park in central Panama (lower left inset map), showing the location of 189 predation events (green dots), release site (white star) and meteorological stations (white triangles).

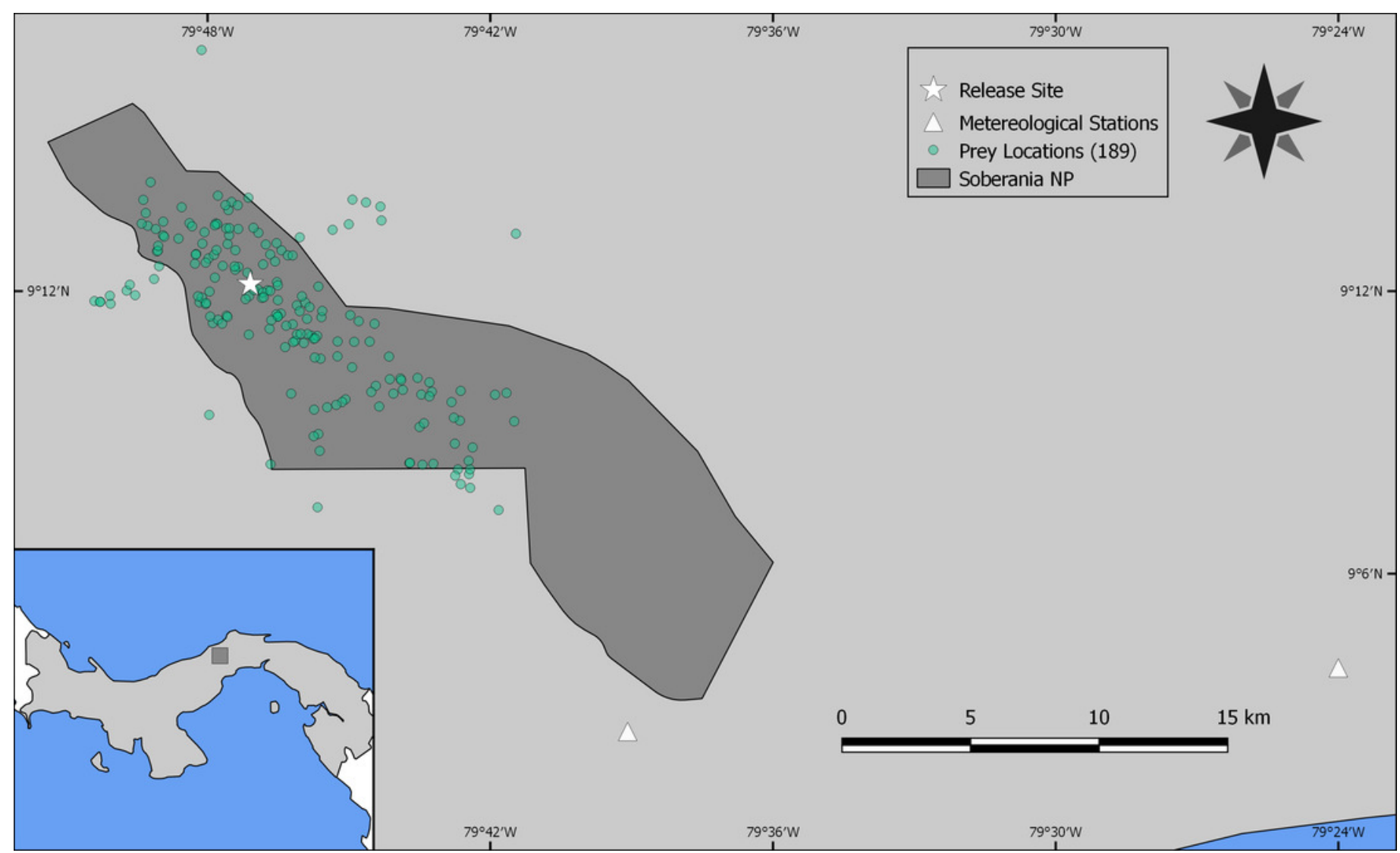




\section{Figure 3}

Fig. 3. Prey composition and effort.

Monthly distribution of harpy eagle kills throughout the year. Vertical bars are color-coded according to the main prey functional groups. Observations were made in all months of the year, however more scantly in November.

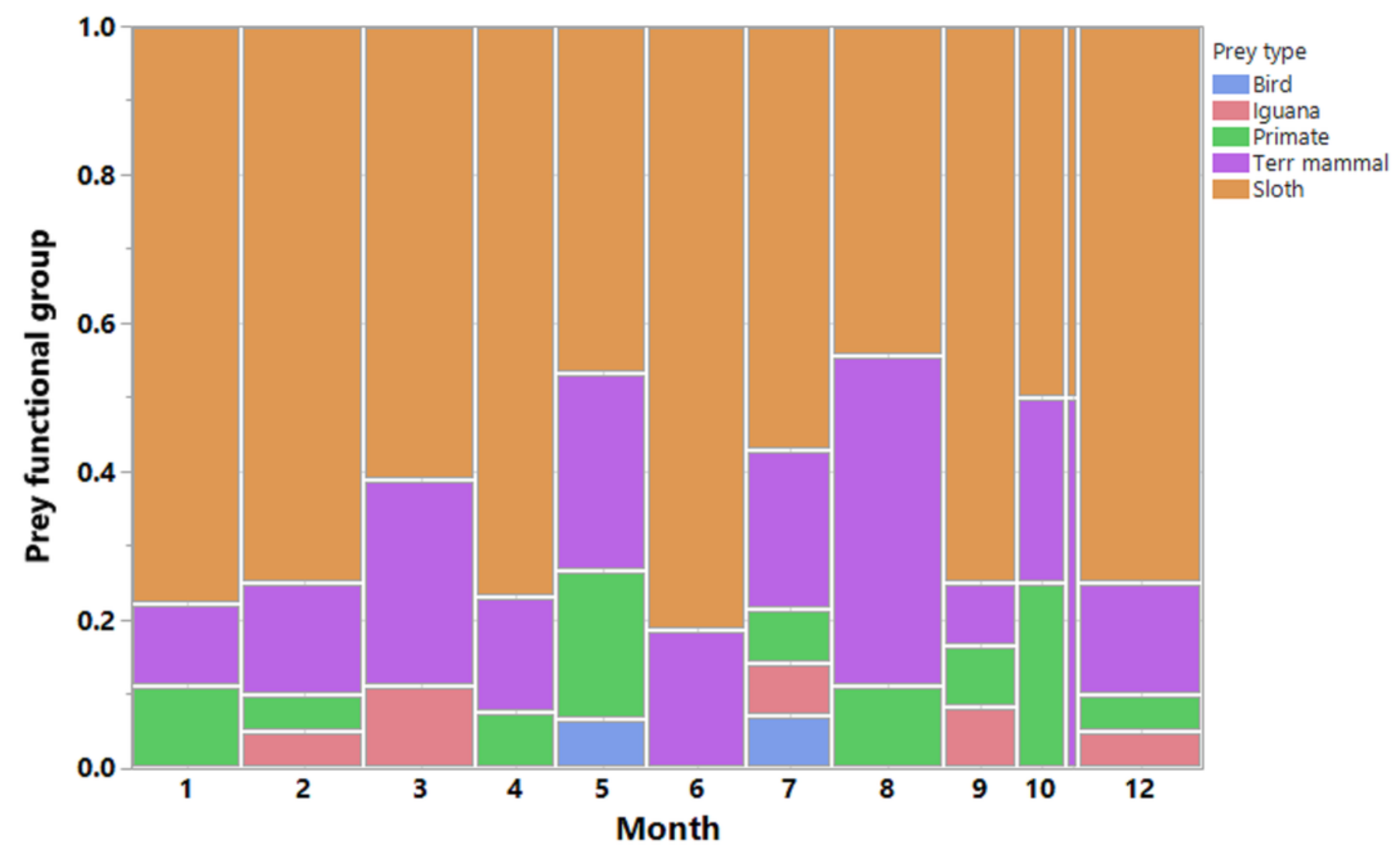




\section{Figure 4}

Effect of environmental variables on the probability of predation events by harpy eagles.

A - Effect of moon brightness on sloth predation probability: fewer sloths were taken during bright moonlit nights $(p=0.0134)$. B - Effect of minimum temperature on sloth predation probability: fewer sloths were taken under cooler conditions $(p=0.0413)$. C - Effect of moon brightness on nocturnal mammal predation: fewer nocturnal prey were killed.during bright nights, but this lacked statistical significance $(p=0.12)$.
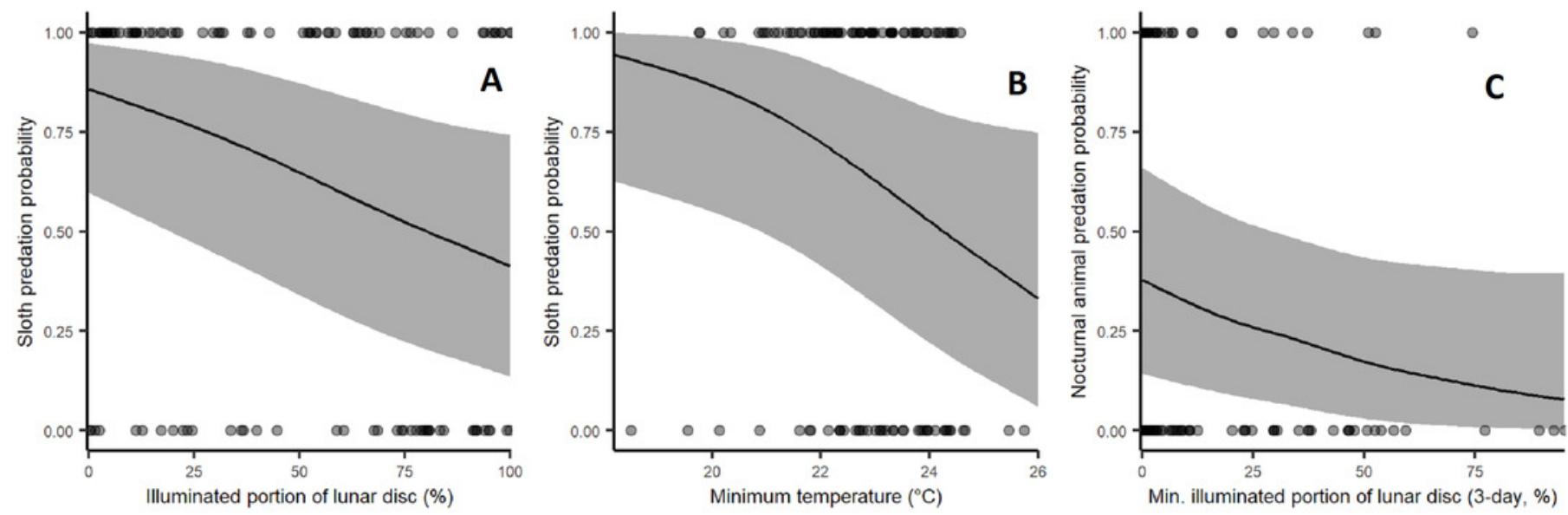


\section{Table $\mathbf{1}$ (on next page)}

Table 1. Prey composition in the diet of harpy eagles.

Seasonal changes in incidence of kills by harpy eagles shown in percentages, combining frequencies for both wet and dry seasons across the seven years of study (2003 - 2009). Overall column shows percentages of prey items for all periods combined, and sample sizes (in parentheses). See "Study Site" section of Methods for further details of season definition. 
1 Table 1. Prey composition in the diet of harpy eagles.

2 Seasonal changes in incidence of kills by harpy eagles shown in percentages, combining

3 frequencies for both wet and dry seasons across the seven years of study (2003 - 2009). Overall

4 column shows percentages of prey items for all periods combined, and sample sizes (in

5 parentheses). See "Study Site" section of Methods for further details of season definition.

\begin{tabular}{|c|c|c|c|}
\hline Species & Dry \% & Wet $\%$ & Overall \% (n) \\
\hline Brown-throated sloth Bradypus variegatus & 36.8 & 31.4 & $34.1(59)$ \\
\hline Hoffmann's two-toed sloth Choloepus hoffmanni & 24.1 & 7.0 & $15.6(27)$ \\
\hline Unidentified sloths & 11.5 & 19.8 & $15.6(27)$ \\
\hline White-nosed coati Nasua narica & 5.7 & 9.3 & $7.5(13)$ \\
\hline Northern lesser anteater Tamandua mexicana & 2.3 & 11.6 & $6.9(12)$ \\
\hline Mantled howler monkey Alouatta palliata & 3.4 & 7.0 & $5.2(9)$ \\
\hline Green Iguana Iguana iguana & 4.6 & 2.3 & $3.4(6)$ \\
\hline Common opossum Didelphis marsupialis & 2.3 & 2.3 & $2.3(4)$ \\
\hline White-headed capuchin Cebus capucinus & 2.3 & 2.3 & $2.3(4)$ \\
\hline Collared peccary Tayassu tajacu & 1.1 & 2.3 & $1.7(3)$ \\
\hline Nine-banded armadillo Dasypus novemcinctus & 1.1 & 1.2 & $1.1(2)$ \\
\hline Central American agouti Dasyprocta punctata & 2.3 & 0.0 & $1.1(2)$ \\
\hline Crab-eating raccoon Procyon cancrivorus & 1.1 & 0.0 & $0.5(1)$ \\
\hline Tayra Eira Barbara & 1.1 & 0.0 & $0.5(1)$ \\
\hline Black vulture Coragyps atratus & 0.0 & 1.2 & $0.5(1)$ \\
\hline Unidentified parrot & 0.0 & 1.2 & $0.5(1)$ \\
\hline
\end{tabular}


$0.0 \quad 1.2 \quad 0.5(1)$

6

Peer] reviewing PDF | (2020:03:46963:2:0:NEW 24 Jul 2020) 


\section{Table 2 (on next page)}

Table 2. Results of generalized linear mixed models of harpy eagle prey profile.

First model predicts probability that a given animal preyed by a harpy eagle is a sloth, while the second model predicts probability of prey being a nocturnal animal. Both models use a logit link due to the binomial natural of the data. Both models use tracked individuals and years sample as random effects over the intercept. 
1 Table 2. Results of generalized linear mixed models of harpy eagle prey profile. First model

2 predicts probability that a given animal preyed by a harpy eagle is a sloth, while the second model

3 predicts probability of prey being a nocturnal animal. Both models use a logit link due to the

4 binomial natural of the data. Both models use tracked individuals and years sample as random

5 effects over the intercept.

\begin{tabular}{ccccccc}
\hline Model & Variable & Estimate & $\begin{array}{c}\text { Standard } \\
\text { Error }\end{array}$ & p-value & $\begin{array}{c}\text { Random } \\
\text { Individual } \\
\text { Variance }\end{array}$ & $\begin{array}{c}\text { Random } \\
\text { Yearly } \\
\text { Variance }\end{array}$ \\
\hline \multirow{3}{*}{ Sloth } & Intercept & 0.588 & 0.470 & 0.2109 & 1.001 & 0.513 \\
& $\begin{array}{c}\text { Lunar disc (\%) } \\
\text { Minimum }\end{array}$ & -0.648 & 0.257 & 0.0116 & - & - \\
& temperature $\left({ }^{\circ} \mathrm{C}\right)$ & -0.508 & 0.263 & 0.0535 & - & - \\
Night & Intercept & -0.933 & 0.422 & 0.0271 & 0.336 & 0.367 \\
& $\begin{array}{c}\text { Minimum lunar disc } \\
\text { (3-Day; \%) }\end{array}$ & -0.392 & 0.269 & 0.1461 & - & - \\
\hline
\end{tabular}

6 